\title{
Preface: Reflections on Emotions
}

\author{
Andrzej Dąbrowski \\ University of Information Technology \\ and Management in Rzeszow, \\ Poland \\ e-mail: adabrowski@wsiz.rzeszow.pl
}

\begin{abstract}
Preface to the special issue 'Reflections on Emotions'. Many academic disciplines have offered important explanations of various aspects of emotion. In the Preface I try to present a wide range of research and stress that study on emotions had its origins in philosophy.

Keywords: emotions, history, philosophy, psychology, psychiatry, economy, sociology, cognitive science, neurobiology.
\end{abstract}

\section{What are Emotions?}

Emotions are an integral part of human beings. They are very important in everyday life: at work, at school, at home, in art, in research, and in every action and conversation. They provide us with effective operation and success. Emotions often are helpful. Often, but not always. Today we know a lot about emotions, however, we still have much to discover. For example, we do not know exactly what emotions are.

There is no definition of emotion that would bind all researchers. Before the eighteenth century philosophers had used such terms as 'passion' or 'affection', and by those they meant among other things: 'strong feelings', 'lust as opposed to reason', 'attraction', 'enthusiasm' or 'inclination'. Emotions were treated as mental states. Presence of the cognitive element, the detailed content or intentionality (directing to a formal object) were underlined. On the other hand psychologists often put stress on the physiological change or the tendency to act. Here are a few selected definitions:

emotion, as conceived by philosophers and psychologists, any of several general types of mental states, approximately those that had been called "passions" by earlier philosophers, such as Descartes and Hume. Anger, e.g., is one emotion, fear a second, and joy a third. An emotion may also be a content-specific type, e.g., fear of an earthquake, or a token of an emotion type, e.g., Mary's present fear that an earthquake is imminent (...) [3, p. 222].

emotion [from Latin e, out + movere, move, agitating motions] Aristotle claimed that emotion, which he called passion [Greek pathos, being acted upon] is a process or motion. Emotions are complex mental states with various degrees of intensity. Unlike 
moods, they are about some real or imagined objects. They give rise to actions or reactions. In this respect, they are associated with the will, but are distinguished from feeling in general because not all kinds of feeling are action-causing. Emotions are accompanied or expressed by bodily symptoms or external behavior. Typical emotions include love, anger, fear, joy, anxiety, pride, contempt, compassion, and indignation, and can occur alone or in combination [4, pp. 205-206].

emotion $n$. a transient, neurophysiological response to a stimulus that excites a coordinated system of bodily and mental responses that inform us about our relationship to the stimulus and prepare us to deal with it in some way [13, p. 179].

emotion $n$. a complex reaction pattern, involving experiential, behavioral, and physiological elements, by which an individual attempts to deal with a personally significant matter or event. The specific quality of the emotion (e.g., fear, shame) is determined by the specific significance of the event. For example, if the significance involves threat, fear is likely to be generated; if the significance involves disapproval from another, shame is likely to be generated. Emotion typically involves feeling but differs from feeling in having an overt or implicit engagement with the world [20, p. 362].

A brief survey of philosophical and psychological dictionary definitions reveals that emotions are numerous, diverse and hard to grasp. So, perhaps the best what we can do is to define them by the idea of the family resemblance. Audi puts it expressis verbis: 'The various states typically classified as emotions appear to be linked together only by overlapping family resemblances rather than by a set of necessary and sufficient conditions' [3, p. 222], but that conclusion may be premature.

\section{Multiple Disciplines Concerning Emotions}

Since childhood we have been learning to recognize and control our emotions. To gain knowledge and understanding of them it is important to have contact with belles-lettres, novels (especially the psychological ones) and drama. Literature describes the internal experiences of heroes; raising, development and acting on their sensations and emotions. The latter may be seen essentially in stories of interpersonal relations and in various ways of experiencing the world. Many people learn about emotions mainly on the basis of literature. On the other hand, there are a lot of research domains that are focused merely on exploring emotions, and they have relevant tools for that.

Contemporarily emotions are mainly a subject of psychology. It searches for their nature and structure; analyzes the course and phases of emotional development. Their kinds and functions are analyzed in detail. The influence of emotions upon human health is examined. On the other hand psychiatry deals with etiology, pathogenesis, symptomatology, mental hospitals and emotional disorder treatment (anxiety, depression, affective disorder). Psychology explores the connection between emotions and cognition, motivation and deciding. It is worth mentioning that the latter is also a field of economic study, where they are linked to the role agents play within the market [7, 8, 9, 16]. Economists and managers search for the possibility to control and use emotions in production and trading.

Essential knowledge referring to how emotions make history is delivered by history of emotions included by the general history. It searches for emotional standards that are obtained in various social groups in various eras, and how and why given institutions and social activities promoted one emotion and depreciated and/or forbade others. The sociology of emotions is concerned with the social conditions of emotions, their dynamics, development, individual, common and organizational work on them. Political researchers indicate the important role of emotions in state, nation, international community, and culture functioning [5, 19]. Cultural anthropology studies emotions in the context of social and cultural differences. 
For the last quarter of the century neurobiology also has explored emotions $[6,11,14]$. Damasio studied brain damage cases and showed that when regions processing emotions are harmed then, even if cognitive abilities remain untouched, the results are problems in decision making and in impulsive disregardful interpersonal behavior.

Structurally, one can distinguish the following possible elements of emotions: pleasant or unpleasant feelings, physiological and neurological states, cognitive and/or appraisal dimensions, behavioral tendencies, facial expression. Emotions may not be reduced to merely one of these components, e.g. to physiological, motivational or cognitive one. All the elements have to be taken into account, elaborately described and explained, and interrelations between them have to be examined. Cognitive science seems to be well-suited for this purpose as an interdisciplinary domain (that includes such areas of research as cognitive psychology, philosophy of mind, neurobiology, artificial intelligence, cognitive linguistics, and anthropology), and especially cognitive neuroscience and/or embodiment approach. On the other hand, cognitive neuroscience concerns emotions merely as far as they influence cognition. In recent time, many investigators have been focused on affective states only, as the result the affective neuroscience has arisen [2, 17].

The science of artificial intelligence also concerns emotions $[1,10,15,18]$. If we want to design humanoid robots to be similar to humans and credible for them emotions have to be included. It is so, because emotions are necessary for intelligent behavior. Those investigations stemmed from the need to have a more adequate idea of artificial intelligence, artificial thinking (there are reasons to consider that real thinking is emotional, and emotions are cognitive and rational), and the need of a more accurate and effective decision making model.

If someone is really interested in affective states, before starting advanced interdisciplinary studies, first maybe they should be familiar with the long history of philosophical investigations concerning emotions. Many thinkers have dealt with these topics in many contexts, usually in moral, social or political, but also cognitive and esthetical one.

\section{Philosophy of Emotions}

This volume focuses on the philosophical studies of emotions. The philosophical tradition of research on emotions is long and the contribution to the understanding of the nature of emotions is large, rich and multiple. The first two articles give some insight into the history of the study of emotions. Andrzej Dąbrowski, in his paper, Emotions in Philosophy - Past and Present Research, begins with a short historical overview, from ancient to modern times. In the article, Ancient Doctrines of Passions: Ethics, Poetics, Rhetoric, Agnieszka Iskra-Paczkowska and Przemysław Paczkowski present Platonic, Aristotelian and Stoic conceptions of emotion. One could ask: why is the history of philosophy important to study? More generally speaking, there are at least three great reasons why the history of philosophy is important indeed. First of all, discovering the historical sources is intellectually exciting. Second, the history of philosophy helps us to better understand contemporary philosophical disputes and the genesis of contemporary scientific problems. Furthermore, it helps us to better understand the nature of human beings, contemporary society and culture.

Philosophical questions are the most fundamental and the most difficult to answer. Cezary Mordka's paper What are Emotions?, raises important questions about emotion: What is emotion as such? What is the structure of emotion? What functions do emotions? Many philosophers in the history of philosophy have regarded thinking and feeling (cognition and emotion) as distinct and have studied it in a strict isolation. In the last decade, many scientists have indicated close links and interactions between both items. Robert Zaborowski, in his paper R. G. Collingwood's Views on the Feeling - Thought Relation and Their Relevance for Current Research, reconstructs Collingwood's position on that dichotomy. It seems that the dichotomy is not as sharp as it is often taken to be. Collingwood nuances his position and Zaborowski makes a case for the interconnectedness of feelings and thought in Collingwood's passages he focuses on. Magdalena Michalik-Jeżowska, in her article About the benefits of pleasure-in-others'-misfortune. Aaron Ben- Ze'ev's depiction of 
emotions as adaptive mechanisms, considers emotions of pleasure caused by someone's bad luck. She focuses especially on adaptive quality of pleasure-in-others'-aging.

People like to have a full control over their behavior and life, even in their emotional life. Formerly many scientists emphasized that emotions are passive and appear independent of us. Today we know that we can control emotions. We can control also their course and strength. In this context of the self-regulation, Anna Pietrzak and Aleksandra Tokarz, in their paper Procrastination as a Form of Misregulation in Context of Affect and Self-regulation, elaborate on role of emotionality in specific domain of self-control that is responsible for reaching important goals. Procrastination is brought in this paper as an example of self-regulatory lapse resulting from prioritising present affect over general well-being.

Dominika Dziurawiec, in her paper 'The Godfather': A Translator's and Writer's Subconscious and Conscious Skills in the Process of Evoking Reader's Emotions, analyzes the influence of particular words on a reader. She investigates the possibility that a translator evokes emotions in a reader, by the means of translation only. She focuses on Italian words occurring in The Godfather by Mario Puzo. Next article is about love - this feeling always fascinated philosophers. In her contribution, The Tectonics of Love in Leo Tolstoy's 'Resurrection', Anna Głąb examines Tolstoy's view of love using some de Sousa's distinctions. The last article entitled Presumptions in Communication is devoted to some conditions and presumptions in speech interaction and it is written by Andrei Moldovan.

\section{References}

1. Adams, R., Dominelli, L., Payne, M. (eds.). Social Work: Themes, Issues and Critical Debates. Palgrave Macmillan: Basingstoke, 2009.

2. Armony, J., Vuilleumier, P. (eds.). The Cambridge Handbook of Human Affective Neuroscience. Cambridge University Press: New York, 2013.

3. Audi R. The Cambridge Dictionary of Philosophy. Cambridge University Press: Cambridge, 1995.

4. Bunnin, N., Yu, J. The Blackwell Dictionary of Western Philosophy. Blackwell: Malden, MA, 2004.

5. Clarke, S., Hoggett, P., Thompson, S. (eds.). Emotion, Politics and Society. Palgrave Macmillan: Hampshire-New York, 2006.

6. Damasio, A. Descartes' Error: Emotion, Reason, and the Human Brain. G. P. Putnam's Sons: New York, 1994.

7. Elster, J. Alchemies of the Mind: Rationality and the Emotions. Cambridge University Press: New York, 1999.

8. Elster, J. Reason and Rationality. Princeton University Press: Princeton-New York, 2009.

9. Elster, J. Emotions. In. P. Hedström, P. Bearman (eds.). The Oxford Handbook of Analytical Sociology. Oxford University Press: Oxford, 2009, pp. 51-71.

10. Johns, M., Silverman, B. G. How emotion and personality effect the utility of alternative decisions: A terrorist target selection case study. In. Proceedings of the Tenth Conference on Computer Generated Forces and Behavioral Representation. SISO, Norfolk, Virginia, 2001, pp. 55-64.

11. LeDoux, J. The Emotional Brain: The Mysterious Underpinnings of Emotional Life. Simon and Schuster: New York, 1996.

12. Loewenstein, G., Lerner, J. S. The role of affect in decision making. In. R. Davidson, H. Goldsmith, K. Scherer (eds.). Handbook of Affective Science. Oxford University Press: Oxford, 2003, pp. 619-642.

13. Matsumoto, L. (ed.). The Cambridge Dictionary of Psychology. Cambridge University Press: Cambridge, 2009.

14. Panksepp, J. Affective neuroscience: the foundations of human and animal emotions. Oxford University Press: New York, Oxford, 1998. 
15. Picard, R. Affective Computing. MIT Press: Cambridge, 1997.

16. Rick, S., Loewenstein, G. The Role of Emotion in Economic Behavior. In. M. Lewis, J. M. Haviland-Jones, L. Feldman Barrett (eds). Handbook of Emotions. Guilford Press: New York, 2008, pp. 619-642.

17. Robinson, M. D., Watkins, E. R., Harmon-Jones, E. (eds.). Guilford Handbook of Cognition and Emotion. Guilford Press: New York, 2013.

18. Sloman, A., Croucher, M. Why robots will have emotions. In. Proceedings of IJCAI 1981. Vancouver, 1981.

19. Thompson, S., Hoggett, P. (eds.). Politics and the Emotions: The Affective Turn in Contemporary Political Studies. Continuum: London, 2012.

20. VandenBos, Gary R. (eds.). APA Dictionary of Psychology. American Psychological Association: Washington, DC, 2015. 